\title{
Satellite telemetry of marine megavertebrates: the coming of age of an experimental science
}

\author{
Kristen M. Hart ${ }^{1,2, *}$, K. David Hyrenbach ${ }^{1,3}$ \\ ${ }^{1}$ Duke University Marine Laboratory, 135 Duke University Marine Lab Road, Beaufort, North Carolina 28516, USA \\ ${ }^{2}$ Present address: US Geological Survey, Florida Integrated Science Center, 3205 College Avenue, Davie, Florida 33314, USA \\ ${ }^{3}$ Present address: Marine Sciences, Hawaii Pacific University, 45-045 Kamehameha Highway, Kaneohe, Hawaii 96744, USA
}

\begin{abstract}
Wildlife telemetry research has expanded greatly in the last 2 decades, with the application of satellite tracking and archival logging technologies to study the ecology and conservation of marine mammals, birds, fishes, and turtles. Widespread and expanding use of satellite tracking to study movements and habitats of marine megavertebrates warrants a review of progress to date and a discussion of challenges facing this rapidly evolving research field. To this end, we reviewed the satellite telemetry literature of air-breathing marine taxa (i.e. birds, mammals, turtles) over the $20 \mathrm{yr}$ time period from 1987 to 2006. This review yielded 92 studies with a wide taxonomic representation: 47 seabirds, 23 sea turtles, and 22 marine mammals. Here we critically evaluate these articles to assess progress in satellite tracking of marine megavertebrates in terms of (1) objectives and approach, (2) experimental design, and (3) reporting of results. The overall trends revealed increases in the duration and scope of tracking studies, yet improvements on experimental design and reporting are needed to facilitate comparisons across studies and species. While inherent ecological differences influence the focus and methods of taxon-specific studies, this review highlights specific areas in need of improvement and provides general suggestions for future tracking studies of marine megavertebrates.
\end{abstract}

KEY WORDS: Megavertebrates - Marine mammals - Seabirds - Sea turtles · Argos $\cdot$ Satellite telemetry $\cdot$ Wildlife telemetry $\cdot$ Review

Resale or republication not permitted without written consent of the publisher

\section{INTRODUCTION}

Technological and conceptual advances in the fields of wildlife tracking, remote sensing, and geographic information systems have stimulated a major leap forward in the understanding of the ecology and conservation of large marine vertebrates, including predatory fishes, marine birds, mammals, and sea turtles (Stone et al. 1999, Block et al. 2002, Coyne \& Godley 2005, Halpin et al. 2009). In turn, these technological and conceptual advances have stimulated major changes in the way ecological research on highly mobile marine organisms is conducted (see reviews by Ropert-Coudert \& Wilson 2005, Wilson \& McMahon 2006, Hooker et al. 2007). In particular, the use of wildlife tracking technologies to study the movements and habitats of marine vertebrates has rapidly expanded since the publication of the first satellite tracking studies of the early 1980s (Godley et al. 2008). In this review, we summarize the development and progress of satellite tracking studies for large marine vertebrates over the last 2 decades, with a focus on airbreathing marine taxa (i.e. seabirds, marine mammals, sea turtles). We assess the current status of this rapidly evolving field and discuss future challenges associated with the use of satellite tracking technologies, especially for threatened and endangered species.

\section{A brief history of satellite tracking}

The first published results of successful satellite tracking of large marine vertebrates involved pioneering deployments of prototype instruments on small 
numbers of animals. These descriptive pilot studies largely focused on establishing the viability of the research techniques and testing modifications in tag design, programming, and attachment (Stoneburner 1982, Priede 1984, Duron-DuFrenne 1987, Tanaka 1987, Stewart et al. 1989, Weimerskirch et al. 1992). The earliest published study involved sea turtles equipped with harnesses tethered to floating buoys (Stoneburner 1982). In this ground-breaking study of 9 nesting loggerhead turtles Caretta caretta tracked during the summers of 1979 and 1980 in the Georgia Bight area of the Atlantic Ocean (USA), researchers documented turtle movements in between successive nesting events, as well as a $19 \mathrm{~d}$ track during the internesting period (Stoneburner 1982, Timko \& Kolz 1982).

The first satellite tracking studies of marine mammals followed shortly thereafter, between 1987 and 1989. Pioneering studies included the tagging of 14 bottlenose dolphins Tursiops truncatus off Japan (Tanaka 1987), the tagging of captive and free-ranging harbor seals Phoca vitulina off southern California (USA; Stewart et al. 1989), the deployment of 3 prototype transmitters on grey seals Halichoerus grypus in the UK (McConnell et al. 1992a), and the first tracking of a humpback whale, Megaptera novaeangliae, for $6 \mathrm{~d}$ off Newfoundland (Canada; Mate 1989).

The first seabird tracking studies focused on the breeding ecology of the larger species, capable of accommodating the transmitters. A proof-of-concept project involving southern giant petrels Macronectes giganteus (Parmelee et al. 1985) was followed by the tracking of 6 wandering albatross Diomedea exulans from January to March 1989. Tagged birds flew 3600 to $15000 \mathrm{~km}$ round-trip flights to provision their chicks at nesting sites in the Crozet Archipelago, southern Indian Ocean (Jouventin \& Weimerskirch 1990).

Pioneering studies aimed at the development of reliable tag attachment techniques often retained instrumented animals in a captive environment (Tanaka 1987, Stewart et al. 1989). Moreover, even when tagged animals were released, premature tag loss or failure often occurred (see review by Stewart et al. 1989). These high rates of tag loss and the highly variable tracking durations characteristic of these early studies (12 min to 35 d, Tanaka 1987; 14 h to 34 d, Stoneburner 1982, Timko \& Kolz 1982), inhibited the design of experimental studies in favor of exploratory research.

Technological advances since the late 1980s have led to the expansion and development of satellite telemetry into an operational research field. In particular, tag miniaturization and novel attachment techniques have expanded the range of study species (e.g. penguins and sea turtles; Eckert \& Eckert 1986, Wilson \& Culik 1994) and allowed for the study of smaller-sized and deepdiving marine mammals, seabirds, and sea turtles
(Mate 1989, Wilson et al. 2002, Eckert 2006, Fossette et al. 2008), while raising awareness of potential deleterious instrument effects on tagged individuals (Phillips et al. 2003, Wilson \& McMahon 2006). The field of study has been even further advanced by the development of tags capable of acquiring concurrent data on animal location, ambient temperature, surface intervals, dive depths, and swim velocity, thus facilitating the first interdisciplinary studies of satellite-tracked individuals and their oceanographic habitats (e.g. McConnell et al. 1992b, Costa 1993, Mate et al. 2005).

Today, satellite telemetry is widely used to characterize movements and habitat use patterns of threatened and endangered megavertebrates (for a history of sea turtle tracking, see Godley et al. 2008). Satellite telemetry is being increasingly used to answer interdisciplinary ecological and resource management questions involving foraging ecology, migratory behavior, and overlap of marine organisms with anthropogenic activities (e.g. management jurisdictions, fisheries, oil and gas exploitation). Moreover, multiinvestigator projects such as the Tagging of Pacific Pelagics (TOPP), BirdLife's Tracking Ocean Wanderers Initiative, and the Dynamics and Management of Ocean Ecosystems (DYNAMOE) program have implemented multi-species satellite telemetry studies involving marine birds, turtles, and mammals (Barlow et al. 2002, Block et al. 2002, BirdLife International 2004). The application of satellite telemetry to inform the management and conservation of marine megavertebrates will continue to expand during the coming decades, with the advent of further technological and conceptual developments. We contend that the widespread use and future potential of satellite telemetry warrant a thorough and critical evaluation of the progress to date and the limitations facing this rapidly evolving field of research.

\section{Objective}

The objective of this review was to help advance the field of satellite telemetry of marine vertebrates by encouraging carefully designed experiments addressing explicit hypotheses and standardized reporting of results across taxonomic groups. To this end, we critically evaluated previously published satellite-tracking studies on marine birds, mammals, and turtles.

\section{MATERIALS AND METHODS}

Scope and approach. We focused this review on the use of satellite-linked transmitters to track large airbreathing marine vertebrates (hereafter referred to as 
'megavertebrates') belonging to 3 distinct taxonomic groups: marine mammals excluding the polar bear Ursus maritimus but including pinnipeds, odontocetes, and mysticetes; marine birds; and sea turtles. The emphasis on these species was driven by their ecological significance as top predators and by their worsening conservation status (Verity et al. 2002, BirdLife International 2004, Halpin et al. 2009). While we address the use of the Argos system, we do not consider the rapidly developing field of wildlife tracking with Geographic Positioning System (GPS) and Global Location Sensing (GLS) technologies. Thus, we refer the readers to other recent reviews of bio-logging and marine wildlife tracking (Schreer et al. 2001, RopertCoudert \& Wilson 2005, Wilson \& McMahon 2006, Hooker et al. 2007).

Publication rates. To assess the publication trends of satellite-tracking papers in the scientific literature, we searched the ISI Web of Science (www.thomsonisi. com) for articles published during the time period 1970 to 2006 using the search terms 'satellite tracking' and 'satellite telemetry.' After removing duplicate citations identified in both searches, we discarded those papers dealing with terrestrial taxa, freshwater species, and marine fishes. Furthermore, we retained papers dealing with the processing of Argos data (e.g. data filtering), but removed papers dealing solely with technical aspects of wildlife tracking (e.g. development of tag attachment methods).

Our review of marine megavertebrate satellite tracking papers focused on 2 explicitly 'marine ecological' journals (Marine Biology [MarBio], Marine Ecology Progress Series [MEPS]) and 2 explicitly 'experimental' journals (Journal of Experimental Biology [JEB], Journal of Experimental Marine Biology and Ecology [JEMBE]). We calculated the proportion (\%) of published articles (excluding errata, editorials, and book reviews) in each journal volume that involved tracking data collected using the Argos system. For each journal, we determined if there were significant patterns in the incidence of Argos papers published during a $20 \mathrm{yr}$ period (January 1987 to December 2006) using simple regression analysis, after transforming the proportional data $(y=\operatorname{arcsine}[x])$ to achieve normality (Zar 1984). The operational null hypothesis was that the slope of the best-fit lines would be indistinguishable from 0 . In addition to performing this analysis for each journal separately, we tested for the effect of journal type ('ecological' versus 'experimental') using a categorical variable ('publication type'). To compare these 4 journals with different numbers of volumes, we combined all issues for every year and analyzed a $20 \mathrm{yr}$ time series (sample size $=20$ yearly values per journal, 80 total). We performed all statistical analyses using Systat 11.0 software.
Literature review. We reviewed and scored 90 articles (listed in an electronic supplement, available at www.int-res.com/articles/suppl/n010p009_app.pdf) involving 92 taxon-specific studies (note: 2 papers reported on multiple taxa), spanning the years 1987 to 2006. We first reviewed each paper independently, and then reconciled any discrepancies in the scores by reviewing articles together a second time. To quantify the current status of this research field, we critically evaluated 3 aspects of each paper: (1) objectives and approach; (2) experimental design; and (3) reporting of results.

Objectives and approach: We first classified the approach followed by the published studies into 1 of 2 possible categories: descriptive (i.e. describing the movements and the habitats of the tagged species) or experimental (i.e. testing specific hypotheses by addressing clearly stated predictions). Throughout this article, we use the term experimental to refer to studies based on experiments, which we define as 'an operation or procedure carried out under controlled conditions in order to discover an unknown effect or law, or to test or establish a hypothesis.' We contrast this experimental research with exploratory studies, whereby 'observations are compiled to describe natural phenomena without the emphasis on testing predictions and developing models' (Merriam-Webster Dictionary online: www.m-w.com).

Next, we classified each paper into 1 or more of 12 possible topics describing the specific purpose of most of the tagging studies we reviewed: politics (POL; i.e. use of protected areas by marine megavertebrates and movements with respect to national jurisdictions); habitat use patterns $\left(\mathrm{HAB}_{\text {; }}\right.$ i.e. the use of different depth, water temperature, and ocean productivity domains); movements (MOV; i.e. activity patterns and foraging ranges); overlap with fisheries and incidental mortality (FIS); species-specific comparisons of movement patterns or habitat use (SPP); differences in movement patterns or habitat use during different life stages (STG); sex-specific differences in movement patterns or habitat use (SEX); differences in movement patterns or habitat use in animals from tagging locations (LOC; e.g. colonies or tagging sites); interannual differences in movement patterns or habitat use (INT); bio-monitoring of the marine environment $(E N V$; i.e. using tagged animals to monitor the physical or biological properties of the marine environment); and methodological comparisons of diverse tracking methods (MET; e.g. deploying multiple tags such as Argos, GPS, and GLS on the same animals, or comparing data processing algorithms on tracks from different types of tags).

Experimental design: We evaluated the experimental design of each published study using 3 quantitative criteria: (1) sex ratio of the tagged individuals; (2) dura- 
tion of the project (i.e. number of years of tracking), and (3) number of tagging sites. These criteria were devised to assess whether studies of animal movements and habitat use patterns investigated sex-based differences, temporal variability (i.e. year to year differences), or spatial variability (i.e. geographic differences). Furthermore, we assessed potential biases from using a single or multiple platform transmitter terminal (PTT) model(s), sex-based differences (i.e. sexual segregation), temporal variability (i.e. from year to year), and spatial variability (i.e. geographic differences) in animal movement patterns and habitat use.

Reporting of results: To quantify the degree to which the reviewed studies provided enough detail to facilitate comparative studies, we recorded how many studies reported (1) instruments used (i.e. number and type of PTT models); (2) total tracking duration (i.e. number of PTT days); (3) quality of location data (i.e. Argos location quality classes [LQCs] obtained and used in subsequent analyses); (4) data processing (e.g. proportion of locations discarded); and (5) data filtering (e.g. the fate of satellite fixes on land).

Trend analysis. To quantify the advancement of the field of satellite telemetry for marine megavertebrates, we used 3 quantitative criteria designed to assess the scope of the published studies over time: (1) sample size of tracking studies; (2) incidence of comparative studies involving multiple species and tagging sites; and (3) use of satellite tracking within a broader interdisciplinary context. We quantified the tagging effort of individual studies using the number of individuals tagged, the overall number of PTT days, the number of species tagged, and the number of tagging study locations. Additionally, to assess the frequency of interdisciplinary studies published in the literature, we assigned each study to 1 or more of 6 possible disciplines: (1) analysis of prey or diet samples; (2) use of stable isotope techniques; (3) analysis of diving and activity patterns; (4) fishery interactions and bycatch; (5) study of energetics and provisioning rates; and (6) use of remotely-sensed environmental data.

After log-transforming the proportional data $(y=$ $\log [x])$ to account for the lack of normality, we used generalized linear models (GLMs) to test for trends in these 6 metrics using a linear regression approach. To account for taxon-specific differences, we also included in the analysis a categorical variable (taxa: bird, mammal, turtle).

To assess whether the objectives and approaches followed by satellite tracking studies were correlated, we compared the proportions of the different topic areas addressed by these 2 approaches (experimental versus descriptive) using a non-parametric rank correlation (Zar 1984). If all research topics were equally amenable to hypothesis testing, we would expect the topic areas to be equally represented in both descriptive and experimental studies. Conversely, if certain topics were more amenable to hypothesis-driven or experimental research, then we would expect a disproportionate representation of the topic areas across the 2 approaches.

Finally, in addition to the somewhat subjective categorical criterion used in this review to contrast 'descriptive' and 'experimental' studies, we quantified the evolution of satellite telemetry studies using several quantitative metrics. We contend that an operational science can be identified by 3 characteristics: (1) broad use (i.e. acceptance within the scientific community); (2) wide applicability (i.e. useful for answering a large range of research questions), and (3) interdisciplinarity (i.e. used in conjunction with other complementary research tools). Thus, we surmised that if satellite telemetry has transitioned from a descriptive to an experimental science, we would expect to see the same patterns that have been documented in other research fields, such as the tools used in geospatial statistics and conservation genetics, which have undergone similar transitions into the 'main stream.' Thus, as satellite telemetry has become more widespread, we would expect the initial proof-of-concept studies to give way to experimental research using standardized techniques with enough replication for rigorous statistical testing. Namely, we anticipated (1) an increasing trend in the sample sizes of satellite tracking studies; (2) a higher incidence of comparative studies involving multiple years, species, and tagging sites; and (3) an increase in the adoption of interdisciplinary approaches, whereby satellite tracking becomes one of the tools in the arsenal used by researchers to answer multi-faceted research questions. We explicitly tested these predictions in our review.

\section{RESULTS}

\section{Publication rates}

Our search of the ISI Web of Knowledge yielded 311 marine megavertebrate satellite tracking papers published in 93 different journals since 1982. Together, the 4 focal journals considered in this review accounted for over one-quarter (90 or $28.9 \%$ ) of all published articles (Table 1). The 2 marine ecological journals (MarBio, MEPS) yielded 78 (96.2\%) of the reviewed papers, and the 2 experimental journals (JEB, JEMBE) yielded 12 articles $(3.8 \%)$.

Regression analyses revealed significant linear increases in the incidence of satellite tracking articles for the 2 marine ecological journals (MarBio and MEPS), but failed to detect a significant trend for the 
Table 1. Summary of the marine megavertebrate articles published in selected focal journals (1987 to 2006)

\begin{tabular}{|lcccc|}
\hline Journal & $\begin{array}{c}\text { No. of volumes } \\
\text { reviewed }\end{array}$ & $\begin{array}{c}\text { No. of articles } \\
\text { reviewed }\end{array}$ & $\begin{array}{c}\text { No. of Argos } \\
\text { papers }\end{array}$ & $\begin{array}{c}\% \text { Argos } \\
\text { papers }\end{array}$ \\
\hline Marine Biology (MarBio) & 246 & 4824 & 18 & 0.37 \\
Marine Ecology Progress Series (MEPS) & 292 & 8091 & 60 & 0.74 \\
Journal of Experimental Biology (JEB) & 337 & 5456 & 6 & 0.11 \\
Journal of Experimental Marine Biology \& Ecology (JEMBE) & 472 & 3937 & 6 & 0.15 \\
Total & 1347 & 22308 & 90 \\
\hline
\end{tabular}

Table 2. Publication trends of satellite telemetry papers in 4 selected journals (1987 to 2006, i.e. sample size is $20 \mathrm{yr}$ ). See Table 1 for journal abbreviations. Bold denotes statistical significance

\begin{tabular}{|lcccc|}
\hline Journal & Coefficient & $t$-statistic & $\mathrm{p}$ & Adjusted $\mathrm{r}^{2}$ \\
\hline MarBio & +0.001 & 3.165 & $\mathbf{0 . 0 0 5}$ & 0.322 \\
MEPS & +0.001 & 5.875 & $\mathbf{0 . 0 0 1}$ & 0.638 \\
JEB & $<0.001$ & 1.426 & 0.171 & 0.052 \\
JEMBE & $<0.001$ & 2.015 & 0.059 & 0.139 \\
& & & & \\
\hline
\end{tabular}

experimental journals (JEB and JEMBE; Table 2, Fig. 1). Our analysis of the entire dataset reinforced the results of the individual time series: we detected a significant increase over time $(F$-ratio $=34.095, \mathrm{df}=1, \mathrm{p}<$ 0.001 ), and a significant difference between the 2 publication types (ecological versus experimental; F-ratio $=20.388, \mathrm{df}=1, \mathrm{p}<0.001)$. Thus, these results suggest that the incidence of megavertebrate satellite tracking studies has increased in the marine ecology literature over the last 2 decades. Although we did not detect a significant increase in the experimental journals, all 12 satellite tracking articles published in these journals

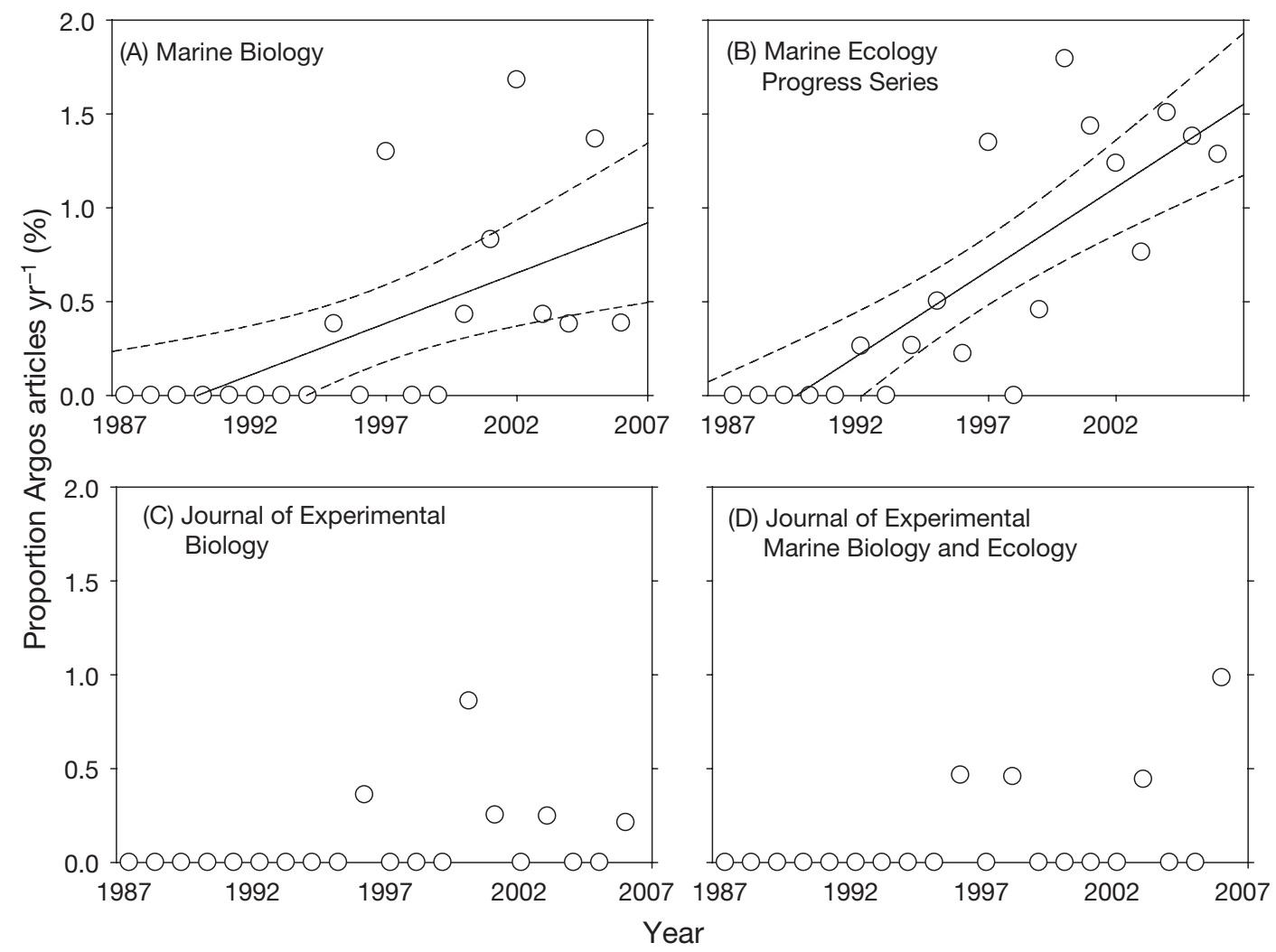

Fig. 1. Time series of satellite tracking articles published in 4 selected journals over a 20 yr period (January 1987 to December 2006), showing the best-fit trends from linear regression analysis (solid line) and the $95 \%$ confidence intervals (dashed lines). Best-fit trends are only shown for significant regressions in $(\mathrm{A}, \mathrm{B})$ 
date from the second decade, and were published after 1995 (Fig. 1).

\section{Literature review}

Our review of the 4 focal journals involved scanning 1347 volumes and 22308 articles published over the 20 yr time period (1 January 1987 to 31 December 2006). This search yielded 90 articles involving the analysis of satellite telemetry data collected using the Argos system from large air-breathing marine vertebrates. Because 2 papers included data from both seabirds and marine mammals (Barlow et al. 2002, Tremblay et al. 2006), we considered them as involving 2 individual studies each. Thus, our sample size for the subsequent analysis consisted of 92 studies involving 1 or more of the 3 taxonomic groups of interest: 47 seabirds ( $52.2 \%)$, 23 sea turtles $(25.6 \%)$ and 22 marine mammals $(24.4 \%)$.

\section{Objectives and approach}

Of the 92 studies we evaluated in this review, $36.7 \%$ tested specific, explicitly-stated hypotheses. The remaining $63.3 \%$ were descriptive studies that characterized the habits and habitats of marine megavertebrates, without testing specific predictions or models. The taxonomic group with the highest percentage of hypotheses-driven studies was sea turtles $(47.8 \%)$, followed by marine mammals $(35.0 \%)$ and seabirds $(31.9 \%)$. However, when we tested for possible taxonspecific differences in the incidence of experimental and descriptive studies using a $G$-test, the analysis of this $3 \times 2$ contingency table yielded a non-significant association between taxonomic group (birds, mammals, turtles) and study approach (experimental, descriptive; $G=1.481, \mathrm{df}=2,0.75<\mathrm{p}<0.50$ ).

The majority of the reviewed studies addressed multiple topic areas $($ mean $=1.4 \pm 0.9 \mathrm{SD}$; range $=0-4$; median $=1, \mathrm{n}=92$ ). The analysis of MOV and HAB were the most popular topic areas across taxa, and were addressed in over $50.0 \%$ of the studies (Fig. 2). The third most prevalent topic area was the use of animals to census the marine environment (i.e. ENV), which was addressed in $28.9 \%$ of the studies. Intraspecific studies of differences in MOV and HAB use patterns across different life-history stages (STA) accounted for $24.4 \%$ of the studies, and interannual differences in MOV and INT accounted for $23.3 \%$. A test of taxon-specific differences in the emphasis of different topic areas revealed a significant association between taxonomic group and topic area $(G=160.10$, $\mathrm{df}=22, \mathrm{p}<0.001)$.

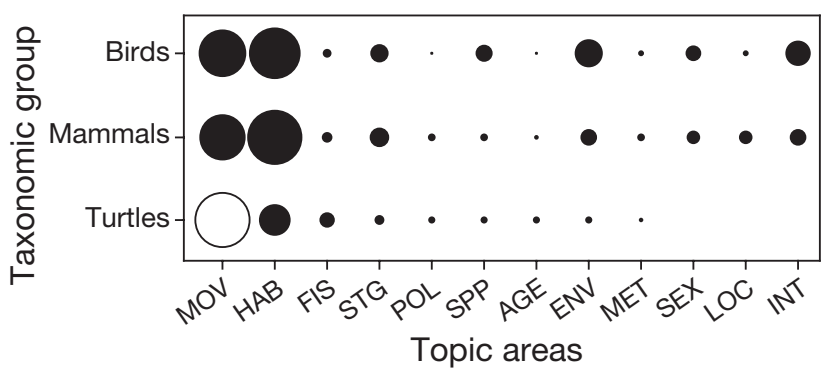

Fig. 2. Proportion of 12 topic areas addressed by satellite telemetry papers. Because studies often address multiple topic areas, the totals for any given taxonomic group exceed $100 \%$. MOV: movements; HAB: habitats; FIS: fisheries; STG: life history stage differences; POL: politics; SPP: species differences; AGE: age differences; ENV: using animals to census the environment; MET: methods test; SEX: sex differences, LOC: tagging site differences; INT: interannual differences. The number of studies varied across taxa: 47 for seabirds, 23 for sea turtles, and 22 for marine mammals. Note that the proportions across all 3 taxonomic groups did not add up to $100 \%$, because studies often addressed multiple topic areas. Thus, the taxon-specific totals were: $200 \%$ (turtles), $304 \%$ (mammals) and $321 \%$ (seabirds). For scale, the open circle highlights the largest proportion of studies addressing a given topic area (87\% sea turtle studies addressed movement)

\section{Experimental design}

Although the number of different PTT models used in a given study ranged widely, we detected a significant difference in the number of studies using 1 or more models across taxonomic groups ( $G$-test $=6.896$, $\mathrm{df}=2,0.05<\mathrm{p}<0.025)$. Over half of the seabird $(63.8 \%)$ and marine mammal $(63.6 \%)$ studies used a single model PTT. In contrast, over half $(52.2 \%)$ of the sea turtle studies used multiple models of PTTs (Table 3). We also found that, on average, $43.5 \%$ of the studies we examined involved $1 \mathrm{yr}$ of tracking. The degree of inter-annual replication, which we equated with the number of tagging studies involving $>1 \mathrm{yr}$, was statistically different among the 3 taxonomic groups $(G$-test $=6.707, \mathrm{df}=2,0.05<\mathrm{p}<0.025)$. A substantially smaller proportion of marine mammal studies spanned only $1 \mathrm{yr}(31.8 \%)$, in contrast with studies of sea turtles $(47.8 \%)$ and seabirds $(46.8 \%$; Table 3$)$. Multi-year studies often lasted $2 \mathrm{yr}$, with only 5 studies spanning $>3 \mathrm{yr}$. The longest study duration was $12 \mathrm{yr}$.

The degree of spatial replication, which we equated with the number of studies that focused on $>1$ tagging site, did not differ significantly across taxa $(G$-test $=1.321$, $\mathrm{df}=2,0.75>\mathrm{p}>0.50)$. Over three-quarters of all the studies $(78.3 \%)$ were conducted at 1 site. Yet, some studies addressed multiple sites, with the maximum number as high as 10 (birds, mammals) and 8 (turtles; Table 3).

The sex of the tracked animals was reported more frequently in studies of marine mammals $(90.0 \%)$ and sea turtles $(87.0 \%)$, with a higher proportion $(46.8 \%)$ 
Table 3. Summary of experimental design for all studies, based on 5 criteria devised to assess whether satellite tracking studies of marine megavertebrates have addressed potential instrument biases (i.e. from using different tags), temporal variability (i.e. from year to year), spatial variability (i.e. geographic differences), and sex-based differences (i.e. sexual segregation) in animal movements and habitat use patterns. Number of studies involved varied across taxa: seabirds (47), sea turtles (23), and marine mammals (22). PTT: platform transmitter terminal; Bold denotes significant differences among taxa

\begin{tabular}{|c|c|c|c|c|}
\hline Metric & Statistics & Birds & Turtles & Mammals \\
\hline No. PTT models & $\begin{array}{l}\text { Range } \\
\text { Mean (SD) } \\
\text { Mode } \\
\% 1 \text { model }\end{array}$ & $\begin{array}{c}1-8 \\
1.5(1.1) \\
1 \\
63.8\end{array}$ & $\begin{array}{c}1-3 \\
1.7(0.8) \\
1 \\
47.8\end{array}$ & $\begin{array}{c}1-8 \\
1.7(1.6) \\
1 \\
63.6\end{array}$ \\
\hline $\begin{array}{l}\text { Sex } \\
\text { (\% unknown) }\end{array}$ & $\begin{array}{l}\text { Range } \\
\text { Mean (SD) } \\
\text { Mode } \\
\% \text { mode }\end{array}$ & $\begin{array}{c}0-100 \\
\mathbf{5 1 . 4}(\mathbf{4 9 . 9 )} \\
100 \\
46.8\end{array}$ & $\begin{array}{c}0-100 \\
\mathbf{1 3 . 0}(\mathbf{3 4 . 4 )} \\
0 \\
87.0\end{array}$ & $\begin{array}{c}0-55 \\
\mathbf{3 . 0}(\mathbf{1 1 . 8 )} \\
0 \\
90.0\end{array}$ \\
\hline $\begin{array}{l}\text { Sex } \\
(\% \text { female) }\end{array}$ & $\begin{array}{l}\text { Range } \\
\text { Mean (SD) } \\
\text { Mode } \\
\% \text { mode }\end{array}$ & $\begin{array}{c}0-78 \\
\mathbf{2 4 . 5}(\mathbf{2 7 . 9 )} \\
0 \\
27.7\end{array}$ & $\begin{array}{c}0-100 \\
\mathbf{8 1 . 0}(\mathbf{4 0 . 2 )} \\
100 \\
73.9\end{array}$ & $\begin{array}{c}0-100 \\
\mathbf{7 3 . 2}(\mathbf{3 4 . 2 )} \\
100 \\
50.0\end{array}$ \\
\hline Study duration (yr) & $\begin{array}{l}\text { Range } \\
\text { Mean (SD) } \\
\text { Mode } \\
\% 1 \mathrm{yr}\end{array}$ & $\begin{array}{c}1-12 \\
\mathbf{2 . 0}(\mathbf{1 . 9 )} \\
1 \\
46.8\end{array}$ & $\begin{array}{c}1-5 \\
\mathbf{2 . 0}(\mathbf{1 . 3 )} \\
1 \\
47.8\end{array}$ & $\begin{array}{c}1-11 \\
3.1(2.6) \\
1 \\
31.8\end{array}$ \\
\hline No. of tagging sites & $\begin{array}{l}\text { Range } \\
\text { Mean (SD) } \\
\text { Mode } \\
\% 1 \text { site }\end{array}$ & $\begin{array}{c}1-10 \\
1.6(1.5) \\
1 \\
76.6\end{array}$ & $\begin{array}{c}1-8 \\
1.4(1.5) \\
1 \\
82.6\end{array}$ & $\begin{array}{c}1-10 \\
1.9(2.3) \\
1 \\
77.3\end{array}$ \\
\hline
\end{tabular}

of seabird papers not quantifying the sex of the tagged individuals. This difference was statistically significant (G-test $=76.873, \mathrm{df}=2, \mathrm{p}<0.001$; Table 3). Moreover, the proportion of females tagged was significantly higher for sea turtles $(81.0 \%$ female $[\mathrm{F}], 6.0 \%$ male [M]) and marine mammals (73.2\% F, 23.8\% M) compared to seabird studies $(24.5 \%$ F, $24.1 \% \mathrm{M}$; G-test $=$ 32.709, $\mathrm{df}=2, \mathrm{p}<0.001$ ).

\section{Reporting of results}

Whereas the PTT models used were consistently reported in all studies, tracking durations were not. $\mathrm{Cu}-$ mulative accounts of tracking days were reported for all 3 taxonomic groups in over $50 \%$ of the studies we evaluated, but sea turtle researchers did so at a higher rate $(87.0 \%)$. Thus, there was a significant taxon-specific difference in the proportion of studies reporting the overall tracking duration, in terms of total number of PTT days $(G$-test $=21.019, \mathrm{df}=2, \mathrm{p}<0.001)$. We attributed this disparity to the higher prevalence of colony-based studies of seabirds and marine mammals, as these studies tended to report the number of foraging trips tracked rather than the actual number of tracking days.

An average of $25.0 \%$ of the evaluated studies reported the proportion of fixes of each LQC obtained and analyzed for turtles $(34.8 \%)$, marine mammals $(31.8 \%)$, and seabirds $(17.0 \%$; Table 4). We detected significant taxon-specific differences in the proportion of studies reporting the LQCs obtained $(G$-test $=9.526, \mathrm{df}=2,0.01<$ $\mathrm{p}<0.005)$ and discarded (G-test $=$ 9.325, df $=2,0.01<\mathrm{p}<0.005$ ) during the analysis (Table 4). Seabird studies reported this information at a lower rate $(12.8 \%)$ than marine mammal $(27.3 \%)$ and sea turtle $(34.8 \%)$ studies.

\section{Trend analysis}

Our review revealed increases in the overall tracking effort per study over time and the tracking duration (quantified using the number of PTT days) over time $(F$-ratio $=10.902, \mathrm{df}=1, \mathrm{p}=0.002)$; with no significant taxon-specific differences $(F$-ratio $=0.783$, df $=2, \mathrm{p}=0.461$; Table 5). The number of tagged animals also increased over time ( $F$-ratio = 10.198, $\mathrm{df}=1, \mathrm{p}=0.002$ ), with a significant taxon-specific difference $(F$-ratio $=11.757, \mathrm{df}=2, \mathrm{p}$ $<0.001)$. More specifically, sea turtle studies were characterized by smaller sample sizes, with $13.0 \%$ of the studies involving only 1 individual (Table 5); seabird and marine mammal studies always involved $>1$ ind.

The incidence of comparative studies through time, quantified as the number of tagging sites and species

Table 4. Evaluation of 4 criteria critical for comparing the methods used in satellite tracking studies of marine megavertebrates: the number of platform transmitter terminal (PTT) models used, the overall study duration (no. PTT days), and the proportions of the Argos location quality classes (LQCs) obtained and discarded in analyses. Number of studies involved varied across taxa: seabirds (47), sea turtles (23), and marine mammals (22). Values shown are the percentages of studies reporting each metric. Bold denotes significant differences among taxa

\begin{tabular}{|lccc|}
\hline Metric & Birds & Turtles & Mammals \\
\hline No. of PTT models & 100 & 100 & 100 \\
PTT days & 61.7 & 87.0 & 63.6 \\
LQCs obtained & $\mathbf{1 7 . 0}$ & $\mathbf{3 4 . 8}$ & $\mathbf{3 1 . 8}$ \\
LQCs discarded & $\mathbf{1 2 . 8}$ & $\mathbf{3 4 . 8}$ & $\mathbf{2 7 . 3}$ \\
\hline
\end{tabular}


Table 5. Trends in the number of individuals tracked, the number of species tracked, and the number of disciplines addressed by each study. Number of studies involved varied among taxa: seabirds (47), sea turtles (23), and marine mammals (22). PTT: platform transmitter terminal

\begin{tabular}{|c|c|c|c|c|}
\hline Metric & Statistics & Birds & Turtles & Mammals \\
\hline No. of individuals & $\begin{array}{l}\text { Range } \\
\text { Mean (SD) } \\
\text { Mode } \\
\% 1 \text { animal }\end{array}$ & $\begin{array}{c}3-179 \\
21.9(29.2) \\
11 \\
0.0\end{array}$ & $\begin{array}{c}1-50 \\
9.4(12.0) \\
1 \\
13.0\end{array}$ & $\begin{array}{c}3-120 \\
26.5(27.1) \\
11 \\
0.0\end{array}$ \\
\hline No. of PTT days & $\begin{array}{l}\text { Sample size } \\
\text { Range } \\
\text { Mean } \\
\text { (SD) } \\
\text { Median } \\
\text { Total }\end{array}$ & $\begin{array}{c}29 \\
38-2753 \\
468.8 \\
(624.6) \\
215 \\
13593.8\end{array}$ & $\begin{array}{c}20 \\
18-5923 \\
1,017.2 \\
(1431.6) \\
525 \\
19326.8\end{array}$ & $\begin{array}{c}14 \\
22-7580 \\
1067.5 \\
(2026.4) \\
436 \\
13441.6\end{array}$ \\
\hline No. of species & $\begin{array}{l}\text { Range } \\
\text { Mean (SD) } \\
\text { Mode } \\
\% 1 \text { species }\end{array}$ & $\begin{array}{c}1-5 \\
1.3(0.7) \\
1 \\
80.9\end{array}$ & $\begin{array}{c}1-3 \\
1.1(0.4) \\
1 \\
95.7\end{array}$ & $\begin{array}{c}1-4 \\
1.2(0.7) \\
1 \\
90.9\end{array}$ \\
\hline No. of sites & $\begin{array}{l}\text { Range } \\
\text { Mean (SD) } \\
\text { Mode } \\
\% 1 \text { site }\end{array}$ & $\begin{array}{c}1-5 \\
1.5(1.0) \\
1 \\
76.6\end{array}$ & $\begin{array}{c}1-8 \\
1.4(1.5) \\
1 \\
82.6\end{array}$ & $\begin{array}{c}1-7 \\
1.6(1.5) \\
1 \\
77.3\end{array}$ \\
\hline No. of disciplines & $\begin{array}{l}\text { Range } \\
\text { Mean (SD) } \\
\text { Mode } \\
\% 1 \text { discipline } \\
\% 0 \text { discipline }\end{array}$ & $\begin{array}{c}0-4 \\
1.5(1.0) \\
1 \\
48.9 \\
12.8\end{array}$ & $\begin{array}{c}0-2 \\
1.0(0.7) \\
1 \\
52.2 \\
21.8\end{array}$ & $\begin{array}{c}0-4 \\
2.0(1.0) \\
2 \\
27.3 \\
4.6\end{array}$ \\
\hline
\end{tabular}

ture (with an average of $2.0 \pm 1.0$ disciplines per study), as opposed to seabirds (with an average of $1.5 \pm 1.0$ disciplines per study) and sea turtles (with an average of $1.0 \pm 0.7$ disciplines per study; Table 5).

Overall, $13.0 \%$ of all the studies we reviewed involved satellite tracking exclusively (i.e. interdisciplinary score of ' 0 '). Of these, $12.8 \%$ involved seabirds, $21.8 \%$ involved sea turtles, and $4.6 \%$ involved marine mammals. Thus, most of the articles we examined used satellite telemetry in conjunction with other tools to obtain a broader perspective of animal movement patterns and habitat use. In particular, the disciplines most commonly addressed by these interdisciplinary studies involved the diving and activity patterns of tagged animals (55.4\%) and the use of remote-sensing imagery $(43.5 \%)$ to characterize habitat use (Table 6). Nevertheless, there were significant taxon-specific differences in the incidence of these disciplines (G-test = 105.335, df $=5, \mathrm{p}<0.001)$. A Spearman rank test of the proportional represen-

addressed in a given study, expanded across the board. The number of tagging sites increased significantly $(F$-ratio $=8.292, \mathrm{df}=1, \mathrm{p}=0.005)$ without evidence of taxon-specific differences $(F$-ratio $=8.292$, $\mathrm{df}=2, \mathrm{p}=0.668)$. However, the number of tagged species over time was not significant $(F$-ratio $=3.254$, df $=$ $1, \mathrm{p}=0.075)$ and showed no taxon-specific differences $(F$-ratio $=1.185, \mathrm{df}=2, \mathrm{p}=0.311)$.

The interdisciplinary nature of satellite tracking studies did not increase over time, with an insignificant increase in the number of disciplines addressed over time $(F$-ratio $=3.219$, df $=1, \mathrm{p}=0.076)$. Yet, there was a significant taxonomic difference $(F$-ratio $=4.725, \mathrm{df}=2, \mathrm{p}=0.011$ ), with a greater number of disciplines addressed in the marine mammal litera-

Table 6. Proportion of the disciplines addressed by satellite telemetry papers

\begin{tabular}{|lcccccc|}
\hline $\begin{array}{l}\text { Taxon } \\
\text { (no. studies } \\
\text { involved) }\end{array}$ & $\begin{array}{c}\text { Diet } \\
\text { samples samples }\end{array}$ & $\begin{array}{c}\text { Isotopic } \\
\text { activity }\end{array}$ & $\begin{array}{c}\text { Fisheries } \\
\text { data }\end{array}$ & $\begin{array}{c}\text { Energetics/ } \\
\text { provisioning }\end{array}$ & $\begin{array}{c}\text { Remote } \\
\text { sensing }\end{array}$ \\
\hline Birds (47) & 40.4 & 0.0 & 38.3 & 4.3 & 12.8 & 51.1 \\
Turtles (23) & 0.0 & 4.3 & 65.2 & 8.7 & 0.0 & 26.1 \\
Mammals (22) & 27.3 & 0.0 & 81.8 & 18.2 & 22.7 & 45.5 \\
Total & 27.2 & 1.1 & 55.4 & 8.7 & 12.0 & 43.5 \\
\hline
\end{tabular}

tation of the different topic areas addressed in descriptive and experimental studies showed a positive correlation $\left(\mathrm{r}_{\mathrm{s}}=0.847, \mathrm{n}=11, \mathrm{p}<0.001\right)$. Because these proportions fell along the 1:1 line, this result suggests that all topic areas are equally conducive to hypothesis testing and descriptive studies (Fig. 3).

\section{DISCUSSION}

This review suggests that the field of satellite telemetry of marine megavertebrates is rapidly growing and developing into an operational science. Our analysis of the incidence of satellite tracking articles in the literature revealed a significant linear increase in 2 marine ecological journals (i.e. MaBio, MEPS; Fig. 1). Yet, despite the publication of satellite-tracking studies in explicitly experimental journals (JEB and JEMBE) starting in 1996, there was no significant increase in the publication rates for these journals (Fig. 1). Thus, whereas our analysis underscores the increase in megavertebrate satellite tracking articles published in the marine ecological literature over the last 2 decades, a pattern previously 


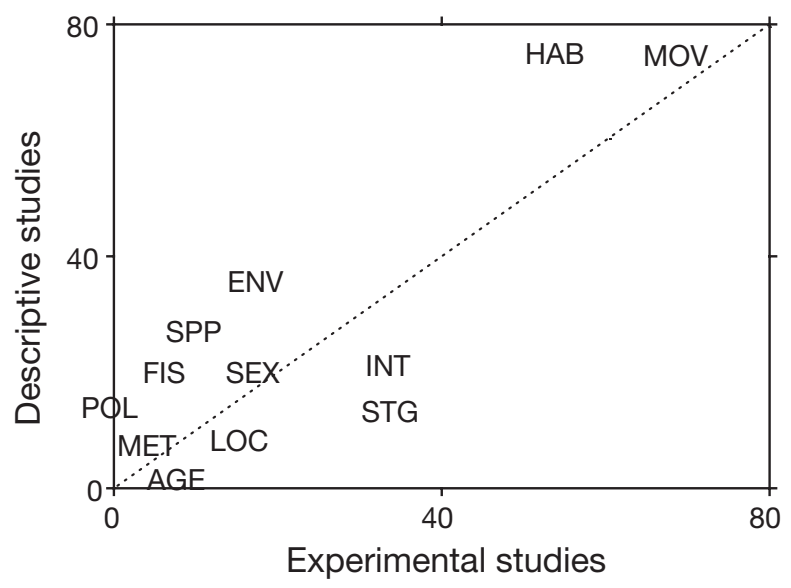

Fig. 3. Proportion of 12 different topic areas within the set of exploratory $(n=57)$ and experimental $(n=33)$ studies considered in this review. Because studies often address multiple topic areas, the totals for any given study type exceed $100 \%$. Dotted line represents a 1:1 line. Abbreviations as in Fig. 2

documented in the sea turtle literature (Godley et al. 2008), it also highlights the lack of satellite-tracking studies in the experimental marine science literature.

Our review also revealed taxonomic differences in the approaches and emphasis of satellite tracking studies of our focal megavertebrate groups. Inherent disparities in the natural history of marine birds, turtles, and mammals greatly influence when and where satellite tags can be deployed, as well as the types of ancillary data that can be collected from satellite-tagged individuals. For example, studies involving the diets and energetics of satellite-tracked organisms are logistically more viable in central-place foraging species, like pinnipeds and seabirds (Gentry \& Kooyman 1986, Wilson et al. 2002), facilitating the integration of multiple research disciplines in a single study.

Nevertheless, researchers in this field can still benefit from the broad-based inter-taxon similarities and differences in the studies conducted to date. In spite of these taxon-specific differences, we found a high incidence of studies involving diving, activity patterns, and remote-sensing imagery across taxa (Table 6), which highlights the desire to interpret the foraging behavior and habitat use of tagged animals in a broader ecological and oceanographic context. The drive to integrate animal movement and environmental data has a long tradition (e.g. Priede 1984, Mate 1989) and is expected to continue in the future (e.g. Block et al. 2002, Hooker et al. 2007). Furthermore, the results of the Spearman rank correlation highlight the potential for undertaking any satellite tracking study using an experimental approach, designed to test predictions and to work towards the development of conceptual models.
Initially, the goal of many early satellite tracking studies was to elucidate animal movement and habitat use patterns (i.e. where do the tagged animals go, where do they spend their time at sea; Godley et al. 2008). Increasingly, however, it is encouraging that researchers are using satellite telemetry to test explicit hypotheses relating to the use of specific oceanic habitats, energy budgets, and fidelity to nesting sites and foraging areas. Improvements in tag performance and attachments have facilitated the use of instruments on smaller-sized individuals, resulting in the expansion of the suite of questions that can be addressed and the species that can be studied using satellite tracking. In addition to these tagging developments, software packages to process and analyze telemetry data (e.g. STAT, Coyne \& Godley 2005) are becoming increasingly available to an ever-expanding user community. Undoubtedly these conceptual and technological advances have been instrumental in transforming satellite telemetry into an operational science that allows researchers to investigate the association of marine megavertebrates with ocean processes at multiple spatial scales (10s to $1000 \mathrm{~s}$ of $\mathrm{km}$; e.g. Polovina et al. 2000, Rodary et al. 2000, Guinet et al. 2001, Hyrenbach et al. 2002).

Our evaluation of the scope of the satellite tracking literature over the last 2 decades showed the anticipated increases in overall tracking effort (number of individuals tracked and PTT days per study) and incidence of comparative studies (involving multiple species and tagging sites). We also found that the interdisciplinary nature of satellite telemetry has expanded over time, with satellite tracking studies addressing an increasing number of research disciplines. Despite substantial taxon-specific differences in the number and types of disciplines addressed by the studies we reviewed, satellite tracking is routinely used in conjunction with other analytical and methodological tools to obtain a broader perspective of animal movements and habitats.

Historical models of scientific development describe a predictable progression in the focus of biological studies. In general terms, the earliest biological studies focus on natural history and field observations, followed by an emphasis on field manipulations, and the eventual development of a more theoretical approach with an emphasis on mathematical analysis and predictive modeling (e.g. Killingsworth \& Palmer 1992, Battalio 1998, Farber 2000). While the development of specific research fields and scientific disciplines is greatly influenced by the methodological and institutional context (e.g. Johnson 2004) and the competition between different scientific communities for resources and prestige (e.g. Johnson 2007), valuable lessons for resource management and conservation can be derived from the historical analysis of research prac- 
tices and publication trends (e.g. Fazey et al. 2005, Pearson \& Cassola 2007).

Without attempting to formally test the development of satellite tracking using a historical model framework, the results of our analysis suggest that this research field is indeed progressing from a descriptive to an experimental science. Whereas the observation of nature and the appreciation for natural history are critical components of any scientific endeavor (Dayton \& Sala 2001, Dayton 2003), scientific progress is enhanced by the systematic development of hypotheses and the testing of model predictions (Platt 1964, O'Donohue \& Buchanan 2001). Thus, we expect that this transition into a hypothesis-driven approach will accelerate the rate of discovery and the overall progress in this research field in future years.

Our motivation for undertaking this review of satellite tracking of marine megavertebrates stemmed from the desire to promote analyses that allow researchers to derive more useful ecological and conservation information from animal movement and habitat use patterns. Moreover, because conservation funding will always be limited, relatively low-cost re-analysis of existing data would represent an efficient use of resources. Thus, we hope this review will stimulate such re-analyses. In particular, studies using standardized techniques will help to identify existing knowledge gaps and data needs to be addressed by future research. Increasingly, these comparative studies will likely involve multiple species from diverse taxonomic groups (e.g. Barlow et al. 2002, Block et al. 2002, Tremblay et al. 2006). To this end, we synthesize this review by offering some suggestions for improving the design of future tracking studies and the reporting of results, with an emphasis on informing natural resource managers charged with the conservation of marine megavertebrates. We also offer ideas for future satellite-tracking studies to facilitate further development of this exciting research field.

\section{CONCLUSIONS AND THE WAY FORWARD}

First, experimental studies will benefit from tagging at multiple sites (to address potential geographic differences) and over multiple years (to address interannual variability). Additionally, studies with larger sample sizes will benefit from a better understanding of individual variability. In particular, there is a paucity of information on the movements of males and juveniles in the sea turtle and pinniped literature. These disparities are likely driven by the focus of turtle and marine mammal studies on the tracking of the accessible females during the breeding season. The return of females to shore to lay eggs (turtles), give birth (pin- nipeds), and provision their pups (fur seals and sea lions) have led to a female-biased sex ratio of the instrumented animals, due to both logistical and ecological biases (Gentry \& Kooyman 1986, Godley et al. 2008). However, future efforts to track both sexes would greatly improve our understanding of the overall movement patterns and habitat use for these species. Although studies focusing on males will not yield information for traditional female-based life tables, including both genders and younger life stages should enhance the ability of managers to provide more comprehensive protection for a species, especially in cases where sexual segregation or age- and size-based dispersal occurs at sea, a common trait of threatened and endangered marine megavertebrates.

Second, another important improvement for future tracking studies entails testing for instrument effects, to determine the energetic demands that different tags place on instrumented animals. Innovative ways to test for the detrimental effects of tags and handling, including assessments of swim speed, diving depth, change in mass over time, differences in trip duration, and regularity of surfacing intervals (i.e. Phillips et al. 2003, Wilson \& McMahon 2006) are much needed. For instance, Fossette et al. (2008) reported significant differences in swim speed and dive depth for endangered leatherback sea turtles Dermochelys coriacea tagged with a traditional 'backpack' harness as opposed to a direct tag attachment. These assessments are critically important to ensure that tagging studies have no adverse effects on the instrumented animals, especially for species of conservation concern.

Third, methodological papers, while relatively new in the literature, are illuminating taxon-specific differences in tag performance, the applicability and performance of data analysis methods (e.g. filtering algorithms), and the use of the same specific ocean habitats. In particular, there has been a recent surge in studies using several different tags (e.g. PTTs in combination or alongside GPS tags) on the same individuals or species. Although researchers must be cautious about the enhanced potential of detrimental instrument effects on study animals, comparative studies involving the use of multiple tags and other data loggers on the same individuals have the potential to greatly accelerate the advancement of this research field. Such multiple-tag studies would allow researchers to study fine-scale foraging and habitat use patterns that are currently difficult to ascertain using only the relatively coarse-scale satellite tracking data.

Fourth, with respect to the reporting of results, we recommend reporting the number of PTT days for each tag in the study and the proportion of Argos LQCs obtained per tagged individual. These statistics pro- 
vide detailed information on the quality of the location data, which are valuable for researchers and satellite tag manufacturers interested in assessing the 'realworld' performance of this technology. Moreover, comparisons across studies would be greatly facilitated if papers reported additional details about the deployment (e.g. exact tag attachment methods) and the performance of the tags (e.g. expected battery life). For instance, whereas tracking durations were consistently reported for all taxa, apparent tag failures (i.e. tags transmitting for a few days or for incomplete foraging trips) were often not discussed. We encourage the evaluation and discussion of tag failures, which is critical information for further advancing this field.

Finally, a detailed description of the filtering and processing of the tracking data is also essential to facilitate comparisons of movement and habitat use patterns. To this end, future studies should provide details of how data were processed and filtered (i.e. best location per day, parameters selected for filtering algorithms), the fate of locations on land, and the number and proportion of different Argos LQCs discarded and used in subsequent analyses.

Although satellite tracking is a rapidly advancing research field, the improvements in study design and reporting that we have outlined here will allow for even greater leaps forward. In particular, it is our hope that this review will promote hypothesis-driven studies involving multiple species and tag types, and interdisciplinary collaborations that inform the effective management and conservation of marine megavertebrates.

Acknowledgements. We thank B. Godley for encouragement and lively discussions about this review, and J. Krebs, K. Mansfield, and A. Tucker for comments on an earlier draft of this manuscript. We are also grateful to K. Johnson and P. Hodum for discussions on the nature of scientific progress. We acknowledge Service Argos for bringing together Argos users at a 2003 wildlife satellite tracking workshop to 'raise the bar,' and are grateful to the researchers who published the satellite telemetry articles we reviewed. Use of trade or product names does not imply endorsement by the US Government.

\section{LITERATURE CITED}

Barlow KE, Boyd IL, Croxall JP, Reid K, Staniland IJ, Brierley AS (2002) Are penguins and seals in competition for Antarctic krill at South Georgia? Mar Biol 140:205-213

Battalio JT (1998) The rhetoric of science in the evolution of American ornithological phases. ATTW contemporary studies in technical communications, Vol 8. Ablex Publishing Corporation, Stamford, CT

BirdLife International (2004) Tracking ocean wanderers: the global distribution of albatrosses and petrels. BirdLife International, Cambridge. Available online at www. birdlife.org/action/science/species/seabirds/tracking.html

Block BA, Costa DP, Boehlert GW, Kochevar RE (2002) Revealing pelagic habitat use: the tagging of Pacific pelagics program. Oceanol Acta 25:255-266
Costa DP (1993) The secret lives of marine mammals. Oceanography (Wash DC) 6:120-128

Coyne MS, Godley BJ (2005) Satellite tracking and analysis tool (STAT): an integrated system for archiving, analyzing and mapping animal tracking data. Mar Ecol Prog Ser 301:1-7

> Dayton PK (2003) The importance of the natural sciences to conservation. Am Nat 162:1-13

Dayton PK, Sala E (2001) Natural history: the sense of wonder, creativity and progress in ecology. Sci Mar 65 (Suppl 2): 199-206

Duron-DuFrenne M (1987) Premier suivi par satellite en Atlantique d'une tortue luth Dermochelys coriacea. CR Acad Sci Ser III 304:399-402

Eckert S (2006) High-use oceanic areas for Atlantic leatherback sea turtles (Dermochelys coriacea) as identified using satellite telemetered location and dive information. Mar Biol 149:1257-1267

Eckert SA, Eckert KL (1986) Harnessing leatherbacks. Mar Turtle Newsl 37:1-3

Farber PL (2000) Finding order in nature: the naturalist's tradition from Linnaeus to E.O. Wilson. Johns Hopkins University Press, Baltimore, MD

Fazey I, Fischer J, Lindenmayer DB (2005) What do conservation biologists publish? Biol Conserv 124:63-73

Fossette S, Corbel H, Gaspar P, Le Maho Y, Georges JY (2008) An alternative technique for the long-term satellite tracking of leatherback turtles. Endang Species Res 4:33-41

Gentry RL, Kooyman GL (eds) (1986) Fur seals - maternal strategies on land and at sea. Princeton University Press, Princeton, NJ

Godley BJ, Blumenthal JM, Broderick AC, Coyne MS, Godfrey $\mathrm{MH}$, Hawkes LA, Witt MJ (2008) Satellite tracking of sea turtles: Where have we been and where do we go next? Endang Species Res 4:3-22

Guinet C, Dubroca L, Lea MA, Goldsworthy S and others (2001) Spatial distribution of foraging in female Antarctic fur seals Arctocephalus gazella in relation to oceanographic variables: a scale-dependent approach using geographic information systems. Mar Ecol Prog Ser 219: 251-264

Halpin PN, Read AJ, Fujioka E, Best BD and others (2009) OBIS-SEAMAP: the world data center for marine mammal, sea bird, and sea turtle distributions. Oceanography (Wash DC) 22:96-107

- Hooker SK, Biuw M, McConnell BJ, Miller PJ, Sparling CE (2007) Bio-logging science: logging and relaying physical and biological data using animal-attached tags. Deep-Sea Res II 54:177-182

> Hyrenbach KD, Fernández P, Anderson DJ (2002) Oceanographic habitats of two sympatric North Pacific albatrosses during the breeding season. Mar Ecol Prog Ser 233: 283-301

Johnson K (2004) The Ibis: transformations in a twentieth century British natural history journal. J Hist Biol 37:515-555

Johnson K (2007) Natural history as stamp collecting: a brief history. Arch Nat Hist 34:110-124

> Jouventin P, Weimerskirch H (1990) Satellite tracking of wandering albatrosses. Nature 343:746-748

Killingsworth MJ, Palmer JS (1992) Ecospeak: rhetoric and environmental politics in America. Southern Illinois University Press, Carbondale, IL

Mate BR (1989) Watching habits and habitats from earth satellites. Oceanus 32:14-18

> Mate BR, Lagerquist BA, Winsor M, Geraci J, Prescott JH (2005) Movements and dive habits of a satellite-monitored 
long-finned pilot whale (Globicephala melas) in the northwest Atlantic. Mar Mamm Sci 21:136-144

McConnell BJ, Chambers C, Nicholas KS, Fedak MA (1992a) Satellite tracking of gray seals (Halichoerus grypus). J Zool (Lond) 226:271-282

McConnell BJ, Chambers C, Fedak MA (1992b) Foraging ecology of southern elephant seals in relation to the bathymetry and productivity of the southern ocean. Antarct Sci 4:393-398

O'Donohue W, Buchanan JA (2001) The weaknesses of strong inference. Behav Philos 29:1-20

Parmelee DF, Parmelee JM, Fuller M (1985) Ornithological investigations at Palmer Station: the first long-distance tracking of seabirds by satellites. Antarct J US 19:162-163

Pearson DL, Cassola F (2007) Are we doomed to repeat history? A model of the past using tiger bettles (Coleoptera: Cicindelidae) and conservation biology to anticipate the future. J Insect Conserv 11:47-59

Phillips RA, Xavier JC, Croxall JP (2003) Effects of satellite transmitters on albatrosses and petrels. Auk 120:1082-1090

Platt JR (1964) Strong inference - certain systematic methods of scientific thinking may produce much more rapid progress than others. Science 146:347-352

Polovina JP, Kobayashi DR, Parker DM, Seki MP, Balazs GH (2000) Turtles on the edge: movement of loggerhead turtles (Caretta caretta) along oceanic fronts, spanning longline fishing grounds in the central North Pacific, 1997-1998. Fish Oceanogr 9:71-82

Priede IG (1984) A basking shark (Cetorhinus maximus) tracked by satellite together with simultaneous remotesensing. Fish Res 2:201-216

Rodary D, Wienecke BC, Bost CA (2000) Diving behavior of Adélie penguins (Pygoscelis adeliae) at Dumont D'Urville, Antarctica: nocturnal patterns of diving and rapid adaptations to changes in sea-ice condition. Polar Biol 23: $113-120$

Ropert-Coudert Y, Wilson RP (2005) Trends and perspectives in animal-attached remote sensing. Front Ecol Environ $3: 437-444$

Editorial responsibility: Steven Cooke, Ottawa, Ontario, Canada
Schreer JF, Kovacs KM, O'Hara Hines RJ (2001) Comparative diving patterns of pinnipeds and seabirds. Ecol Monogr 71:137-162

Stewart BS, Leatherwood S, Yochem PK, Heide-Jørgensen MP (1989) Harbor seal tracking and telemetry by satellite. Mar Mamm Sci 5:361-375

Stone G, Schubel J, Tausig H (1999) Electronic marine animal tagging: new frontier in ocean science. Oceanography (Wash DC) 12:24-27

Stoneburner DL (1982) Satellite telemetry of loggerhead sea turtle movement in the Georgia Bight. Copeia 1982: $400-408$

Tanaka S (1987) Satellite radio tracking of bottle-nosed dolphins Tursiops truncatus. Nippon Suisan Gakkaishi 53: $1327-1338$

Timko RE, Kolz AL (1982) Satellite sea turtle tracking. Mar Fish Rev 44:19-24

> Tremblay Y, Shaffer SA, Fowler SL, Kuhn CE and others (2006) Interpolation of animal tracking data in a fluid environment. J Exp Biol 209:128-140

Verity PG, Smetacek V, Smayda TJ (2002) Status, trends and the future of the marine pelagic ecosystem. Environ Conserv 29:207-237

Weimerskirch H, Salamolard M, Jouventin P (1992) Satellite telemetry of foraging movements in the wandering albatross. In: Priede G, Swift SM (eds) Wildlife telemetry. Ellis Horwood, New York, NY, p 186-198

Wilson RP, Culik B (1994) Hydrodynamic aspects of design and attachment of a back-mounted device in penguins. J Exp Biol 194:83-96

Wilson RP, McMahon CR (2006) Measuring devices on wild animals: What constitutes acceptable practice? Front Ecol Environ 4:147-154

Wilson RP, Gremillet D, Syder J, Kierspel MAM and others (2002) Remote-sensing systems and seabirds: their use, abuse and potential for measuring marine environmental variables. Mar Ecol Prog Ser 228:241-261

Zar JH (1984) Biostatistical analysis, 2nd edn. Prentice-Hall International, Englewood Cliffs, NJ

Submitted: November 20, 2007; Accepted: September 18, 2009 Proofs received from author(s): December 6, 2009 